\title{
El archivo como productor: el lugar del uso en El deseo nace del derrumbe, de Roberto Jacoby
}

Irina Ruth Garbatzky*

Resumen: Durante la primera década del 2000, varias experiencias artísticas, poéticas y políticas de las vanguardias argentinas del ' 60 y de ciertos movimientos contraculturales del proceso de recuperación democrática han sido objeto de numerosas investigaciones, muestras retrospectivas, archivos y documentales. La condición ciertamente expansiva de dicha serie nos trae la observación acerca de una puesta en peso de la noción de archivo: no sólo como reunión y domiciliación de un conjunto documental, sino como herramienta conceptual idónea para un pensamiento sobre las materialidades en las artes y en la literatura. En el presente artículo se aborda, a partir de una perspectiva foucaultiana del archivo (como sistematización y normativa de emergencia de los discursos), un entramado discursivo en torno al rol del archivo como productor no sólo de relatos críticos sobre la tarea de archivar sino, especialmente, como dispositivo de uso de bienes culturales comunes. Dicho dispositivo intervendría en la tensión vanguardia/ musealización abriendo nuevos lugares de problematización de lo político. Para ello se rastrea en el volumen El deseo nace del derrumbe. Acciones, conceptos y escritos, de Roberto Jacoby (Ana Longoni compiladora) (2011), distintos momentos en los cuales la estrategia del uso se encontraba vinculada a su práctica artística.

Palabras clave: Archivos. Vanguardia argentina. Roberto Jacoby. Museificación. Textos de artistas.

\footnotetext{
* Doctora en Humanidades y Artes. Mención Literatura, por la Universidad Nacional de Rosario (Argentina).UNR/CONICET-Argentina. E-mail: irinitag@gmail.com.
} 


\section{Introducción}

Cuando Arlette Farge estudiaba los archivos policiales de París del siglo XVIII, fascinada por el efecto de verdad que provocaba el registro táctil de algunos documentos - la carta de un preso a su esposa, escrita sobre un retazo de sábana, el informe de un médico acompañado por un pequeño saco de tela -, entendió que, justamente en virtud de esa atracción irresistible, el historiador debía insertar la vitalidad de esas piezas "[...] en una escritura que haga perceptibles las condiciones de su irrupción" (1991, p. 61). Para ello debía sortear tanto la trampa literaria como la datación histórica hegemónica:

Cuando, por ejemplo, se pregunta a un buhonero, sospechoso de robo, en qué año nació y contesta: "no sé el año, pero hará 17 años el día de San Carlos”, sería una lástima anotar tranquilamente en la ficha, "17 años", en el apartado edad, pues faltaría todo cuanto sumerge esta información en un universo al mismo tiempo personal y colectivo (1991, p. 64-65).

A diferencia de los datos fríos de las nóminas, el investigador debía llevar adelante un ejercicio sensible: no para escribir una novela, por supuesto, sino para comprometerse con las voces soterradas que el documento dejaba escuchar. La resolución entonces no estaría en manos de la ilusión que cada pieza de un archivo producía - la de dar cuenta del pasado como totalidad -, sino en la versatilidad del investigador para producir su sentido y mostrar su potencialidad crítica, a partir, precisamente, de dicha inestabilidad. El archivo, de este modo, convocaría menos a constatar un acontecimiento que a producir otro en el curso de la historia.

Remitirnos a Farge nos sirve para iniciar un pensamiento acerca de cuáles son los efectos que produce sobre la cultura la creciente organización en archivos y muestras retrospectivas de experiencias y obras artísticas sumamente dispersas; vinculadas, en diversos grados, con las herencias del conceptualismo y la desmaterialización del objeto artístico de las vanguardias del sesenta y

Anos 90, Porto Alegre, v. 21, n. 40, p. 311-331, dez. 2014 
con distintas formulaciones del cuerpo durante los comienzos de la democracia en Argentina. En efecto, aunque ya hacia mediados de los años noventa, Andreas Huyssen (1995) advirtió sobre el giro a la memoria como efecto de la saturación de la información propia de la cultura massmediática, la pregunta sobre las posibilidades productivas de los archivos y sus condiciones de aparición parecería ser todavía una cuestión crucial para articular nuestro presente. No sólo a causa de que, efectivamente, durante la primera década del 2000, dichas muestras retrospectivas, archivos y documentales se encuentren en expansión en Argentina y Latinoamérica; sino porque a su vez, estas muestras, publicaciones y filmes nos traen la observación acerca de una puesta en peso de la noción de archivo, no sólo como reunión y domiciliación de un conjunto documental, sino en tanto, por un lado, herramienta conceptual idónea para un pensamiento sobre las materialidades en las artes y en la literatura - especialmente cuando el problema que se presenta resulta el de cómo articular relatos o corpus artísticos cuya condición objetual resulta sumamente precaria -, y por otro, como cuestionamiento acerca de los medios por los que sería posible reactivar la memoria de poéticas emancipatorias. ${ }^{1}$ El lugar del archivo en la reactivación de los legados de las vanguardias viene siendo abordado desde diversas perspectivas que transitan, sobre todo, la problemática de la transmisión y la memoria de las búsquedas de transformación de la vida y la sociedad que las mismas impulsaron. ${ }^{2}$ En este sentido, intentaremos realizar un aporte que, sin negar la radicalidad del debate, se proponga una pregunta alternativa acerca de la operatividad del archivo como productor de valores y discursos. Para ello, el caso de El deseo nace del derrumbe. Acciones, conceptos y escritos - un libro que es asimismo el catálogo de la muestra homónima sobre la obra del artista Roberto Jacoby, realizada en el Museo Nacional Centro de Arte Reina Sofía de Madrid durante mayo de 2011 - se ofrece de manera ejemplar, ya que colocó de manera explícita la idea del "archivo en uso" de la totalidad de la obra de un artista. A su vez, el libro articula los aportes de un colectivo de investigadores y la tarea de edición compartida entre el curador y el archivista junto al artista, una triangulación crucial durante los últimos años que vuelve a proyectar, entre otras cosas, el desmantelamiento de las categorías de 
obra, autor, producción original y única. Y que evidencia, a su vez, un efecto: la obra desmaterializada de Jacoby provoca una proliferación textual desbordante; El deseo... muestra los caminos por los cuales el archivo hoy puede potenciar las búsquedas de desmaterialización y colectivización que trazaron la historia, absolutamente ligada a la vanguardia, de la praxis artístico-vital de Jacoby.

Interesa, pues, mencionar algunos antecedentes para tratar de determinar los alcances que poseen dichas miradas retrospectivas. Para ello, será preciso colocar en primer plano la particular definición que Michel Foucault entendió por "archivo", ya hacia finales de la década del sesenta; ni la suma de los textos o de lo dicho, ni las instituciones de guarda o de registro, sino la normativa que produce su emergencia: "el sistema que rige la aparición de los enunciados como acontecimientos singulares [...] la práctica que hace surgir una multiplicidad de enunciados como otros tantos acontecimientos regulares, como otras tantas cosas ofrecidas al tratamiento o la manipulación" (1979, p. 219-221). La performatividad de los archivos en la cultura no redundaría entonces únicamente en la producción de hallazgos novedosos para las artes o la investigación, sino en los discursos que emergen a partir de afirmar la importancia de que determinadas acciones artísticas (y la materialidad de sus restos) sean recuperadas, exhibidas y conservadas.

Uno de estos discursos es el que propone al archivo como la ocasión de uso de un patrimonio común, el dispositivo de su socialización.

Ciertamente la tensión que la musealización imprime sobre los archivos, su riesgo constante de convertirse en objetos absolutamente contrarios a la desestabilización del mercado del arte que originalmente promulgaban, demanda la propia elaboración de un relato crítico en torno al lugar de su emergencia. De modo que el segundo efecto de la puesta en peso del archivo se acompaña bien de las observaciones de Farge citadas al comienzo: las retrospectivas no sólo exhiben, sino que a su vez construyen una reflexión sobre qué significa la tarea de archivar, de qué formas el archivo se mantiene siempre abierto y cuáles son las condiciones de ubicación de sus propios productos dentro de las coordenadas políticas que les dieron lugar. Mediante el archivo como oportunidad de uso de los

Anos 90, Porto Alegre, v. 21, n. 40, p. 311-331, dez. 2014 
bienes culturales y el archivo como efecto de un relato crítico, por tanto, atisbaríamos, con la dificultad que conlleva leer el presente, el entramado discursivo al que nos estamos refiriendo.

\section{El archivo como lugar de uso}

Antes de centrarme en la experiencia de El deseo nace del derrumbe, quisiera trazar una breve digresión para plantear su hipótesis de lectura. Si tomamos la perspectiva foucaultiana con el fin de entender al archivo en tanto normativa de emergencia de los discursos, sería pertinente, como dijimos, preguntarnos qué discursos se estarían trazando en el haz de dificultades que concierne a dicha recopilación y domiciliación de obras o movimientos que se plantearon como radicalmente reticentes al registro y la exposición.

En el centro del debate acerca de la conversión de los museos en sitios de espectacularización masiva y massmediática (CANCLINI, 1992; 2010; AGAMBEN, 2005), del trasvaso de los acervos de las vanguardias a objetos de muestras y exhibiciones, uno de los discursos de mayor relevancia tiene que ver, de manera general, con el potencial productor de los archivos. La cuestión del uso del archivo parece fundamental para pensar buena parte de las retrospectivas de los últimos años y abre una encrucijada en la tensión surgida frente a la estabilización de obras que fueron pensadas por fuera y en conflicto con su dimensión exclusivamente objetual. Dicho uso de los archivos no debería entenderse tanto desde una dimensión profanadora, que enfrente al Museo como espacio de consagración (AGAMBEN, 2005) ni como una reinserción de los procedimientos de las vanguardias de 1920 o 1930, siguiendo el modo cuestionado por Frederic Jameson (1984) y Andreas Huyssen (1986) o reinstalado por Nicolas Bourriaud (2007). ${ }^{3}$ La idea de uso en estos contextos envuelve una pregunta sobre cómo hacer converger el "valor de exposición", que inevitablemente gira sobre las muestras retrospectivas y la exhibición de documentos, con una comprensión del archivo como bien común, que pone a disposición de la sociedad el conocimiento generado por la tarea de archivar y que por lo tanto debe incentivar políticas públicas para la preservación de los registros

Anos 90, Porto Alegre, v. 21, n. 40, p. 311-331, dez. 2014 
y colecciones. En este punto, las articulaciones entre los curadores, los artistas y sus archivos, los investigadores y los directores de los museos compondrían una singular cercanía con prácticas colectivas de producción y distribución de bienes culturales.

Recordemos que el concepto "valor de exposición" o "valor exhibitivo" (Ausstellungswert) según Walter Benjamin (1935), se deslindaba tanto del valor de uso de la mercancía como de su valor de cambio y emergía como parte del proceso de la reproductibilidad técnica de la obra de arte. ${ }^{4}$ En la oposición marxiana entre valor de uso y valor de cambio, sostiene Giorgio Agamben, el valor de exposición planteaba un tercer término, que no se dejaba reducir a los dos primeros. "No es valor de uso, porque lo que está expuesto es, en tanto tal, sustraído a la esfera del uso; no es valor de cambio, porque no mide en modo alguno una fuerza de trabajo" (AGAMBEN, 2005, p. 116-117). No ingenuamente, pues, retorna la valoración del uso en torno al arte. Convocar este mapa de asociaciones en torno a los archivos, forma parte de un punto de vista teórico y una estrategia política para problematizar desde adentro de las instituciones aquellas tensiones que fueron clave para la modernidad. En 2008, por ejemplo, en el catálogo de Inventario 1965-1975 de Graciela Carnevale, la muestra de los archivos de Tucumán Arde realizada en los túneles del Centro Cultural Parque de España de Rosario, dicha disposición en relación al uso se hacía explícita:

Nota sobre el uso: La publicación del siguiente inventario es concebida con el propósito de socializar en detalle el contenido del Archivo Graciela Carnevale en el período que se extiende de 1965 a 1975; y a su vez como puesta al alcance de una herramienta de uso para venideros estudios de especialistas o consultas de cualquier interesado. Entre el catálogo y la muestra existen diferencias y superposiciones: el primero excede a la segunda en tanto que potencia los elementos publicados por fuera dándolos a conocer para su uso; a su vez, la muestra supera a este inventario con la exposición de materiales posteriores a 1975 en calidad de derivas que fueron dándose hasta la actualidad. (CARNEVALE et al., 2008, p. 9, el subrayado es mío). 
Es sabido que la producción gráfica de Tucumán Arde (la acción artística que en 1968 buscaba denunciar y contrainformar, durante el período dictatorial transcurrido entre 1966 y 1973, las condiciones de pobreza en la provincia argentina frente al cierre de las azucareras), ${ }^{5}$ no fue pensada para insertarse en circuitos de exposición. Es el entramado discursivo sobre el uso el que valida hoy la exposición de los documentos de una de las obras más canonizadas y míticas del arte argentino. Y dicho entramado propone la formulación de estrategias de diseminación de su documentación: en este caso, mediante fotocopias accesibles para los visitantes o mediante la elaboración de un catálogo que coloque públicamente la información de un material hasta entonces, para decirlo con palabras de Jacques Derrida (1997), an-archivado, es decir, sujeto a la dimensión privada del nombre propio. A partir de una organización ramificada, que recababa lo recopilado por Carnevale y el material donado por otros participantes de esa experiencia, la tarea de los investigadores daba un paso, de este modo, hacia el sentido de bien público que todos los Archivos sustentan.

Sumamente ligada a la vanguardia de los años sesenta, al valor otorgado a la circulación desmaterializada de la obra y al arte entendido como crítica institucional, la idea de la democratización del archivo abre otras aristas que vale, al menos, señalar. Según Andrea Giunta (2010), la tarea de desclasificación de archivos no debería deslindarse de la tarea de desclasificar políticas de conocimiento, es decir, de asociarse con programas de investigación o de producción crítica. ${ }^{6}$ De dicho señalamiento (el vínculo "políticas de archivo" "políticas de conocimiento"), más allá de la inserción de los archivos dentro de un sistema global y "bienalizado" de las artes, ${ }^{7}$ se podría inferir que las tareas de recuperación de documentaciones al tiempo que democratizan también intervienen sobre qué se torna archivable, qué recursos se convierten en indispensables y cuáles son las mejores estrategias para su conservación. Esto conduce tanto a cuestiones sobre políticas científicas como a la posibilidad de una pregunta sobre el tipo de materialidad de los objetos de estudio, cuál es el límite en la incorporación del fragmento, del resto o de la huella en los corpus de las muestras o de las investigaciones y qué efectos producen estos usos sobre la idea de una totalidad de la historia.

Anos 90, Porto Alegre, v. 21, n. 40, p. 311-331, dez. 2014 
En un sentido o en otro, nunca dejamos de encontrarnos frente a la noción del archivo como productor: no sólo por la posibilidad de reutilización estética de sus materiales sino como producción de conocimiento y de herramientas de análisis intelectual, como dispositivo de democratización del saber y de las formaciones artísticas, @ como lugar de confección (política) de objetos de estudio.

\section{Que no sea sólo para leer. Que sea para usar}

El deseo nace del derrumbe encuentra varias similitudes con Inventario, no sólo en cuanto al equipo de investigadores intervinientes. ${ }^{8}$ La noción de "archivo en uso", reaparece como el discurso articulador del libro: si la obra de Jacoby perseguía la metáfora de la demolición de presupuestos y compartimentos estancos entre las categorías arte, vida, política, tecnología, amistad, El deseo..., sostiene Ana Longoni en el prólogo, despliega una observación:

La franca dispersión de ámbitos, intereses, formatos y referencias teóricas que parece un rasgo constitutivo de Roberto Jacoby, [...] evidencia todo lo contrario: la insistencia de un conjunto de [...] ideas-fuerza que emergen, toman consistencia, se reformulan, cambian de forma, se vuelven más precisas, se abandonan (LONGONI, 2011, p. 10).

Así, lo que se organiza de la dispersión es el archivo y su principio constructor es la hipermedialidad. El libro presenta entradas múltiples, por "conceptos-fetiche" y "núcleos epocales". Cada capítulo supone un período histórico y se segmenta en "Conversaciones" y "Documentos". En una lectura, (la estructura reticular permite un abordaje lineal o transversal), se podrán seguir estas entradas que funcionan como un link, cuya historia detallada se completa en un anexo final, con un "glosario de nombres y acontecimientos clave" y un "mapa de conceptos fetiche".

El libro expone un enorme conjunto de documentos que Jacoby guardaba en su casa y los somete a más de un punto de vista: no sólo del lector, sino, en primera instancia, del propio autor, cuyas 
entrevistas, realizadas por el equipo de investigadores vinculados a la edición y otras personas a lo largo de los años, son fragmentadas y vueltas a montar en relación con la temática y la época histórica de cada capítulo. En la entrada escrita al comienzo de cada sección o en algunas notas al pie, Jacoby disiente o afirma lo que ha dicho en determinado momento. Es decir, El deseo... no arma un archivo estabilizado o una antología cerrada, sino que es continuamente revisitado, comentado y rearticulado por la mirada del autor, de los historiadores y los entrevistadores, manteniendo, como en casi toda su obra, la metáfora de la red como dispositivo de acceso. ${ }^{?}$ "Archivo en uso", además, aparece como la formulación teórica para conceptualizar el proceso de la investigación y su socialización pública; así se denominaba la sección hipermedial de la muestra que los visitantes podían consultar en el Museo, cuya base de datos fue distribuida en distintas instituciones educativas de Latinoamérica. ${ }^{10}$

En este punto, es necesario advertir que el entramado discursivo en torno a la validación del arte en función del uso y el intercambio ya tenía dentro de los propios planes artísticos de Jacoby su propia historia. En el vasto volumen de más de quinientas páginas, ello puede leerse en al menos dos oportunidades. La más conocida, por ser una de las más recientes, fue el Proyecto Venus, que tuvo lugar entre 1999 y 2006, cuando una serie de experimentaciones ligadas a lo colectivo, que llevaban a su vez las marcas de la crisis económica (la revista ramona como primera revista de artes sin imágenes, de pocas páginas y repartida gratuitamente, el proyecto Bola de nieve, como red de difusión de artistas visuales), dieron lugar a una plataforma que consistía en el intercambio de bienes o servicios a partir de una moneda inventada, también llamada Venus. El proyecto resonaba con otros emprendimientos autogestivos ligados a la crisis económica de comienzos del 2000, como los clubes de trueque o las asociaciones barriales, así como con las monedas inventadas por el Estado en ese coyuntura (los Patacones y los Lecops). Se trataba de la elaboración de un mercado no convencional, que apuntaba a la "cooperación directa entre personas concretas" (JACOBY, 2011, p. 378), un lenguaje entre la oferta y la demanda que autorizaba no sólo a intercambiar cosas preexistentes sino a inventar otras. Así se describía el proyecto en 1999:

Anos 90, Porto Alegre, v. 21, n. 40, p. 311-331, dez. 2014 
El archivo como productor: el lugar del uso...

\section{Instrucciones para su uso:}

Usted recibe una pequeña cantidad de billetes venus con su entrada y puede cambiarlos inmediatamente por algo que desee poseer más que una pieza de arte de museo: una cerveza, un café, un catálogo, un regalo en el shop de la Galerija.

Pero también puede intercambiarla con otros concurrentes a la Galerija: 100 venus por un beso, por ejemplo.

Usted puede convertirse en un especulador en venus y acumular grandes cantidades de estos billetes.

Usted puede robar venus a los concurrentes a la Galerija.

Usted puede vender sus venus al cambio local si encuentra demanda.

Usted puede crear su propia comunidad deseante que acepta exclusivamente venus en sus intercambios. (1999, p. 403). ${ }^{11}$

El Proyecto Venus formaba parte de una investigación con varias claves (sociológicas, políticas, económicas), entre ellas la escenificación de una relación creciente de la cultura con estrategias de autofinanciamiento. Sólo que, en lugar de enmarcarse en el circuito de galerías y bienales, dicha productividad se ubicaba en la confección de espacios y vinculaciones cotidianas y azarosas, sostenida por la dinámica horizontal de las relaciones. La plataforma llegó a tener más de quinientos inscriptos que intercambiaban de todo, desde corrección de textos hasta obras de arte, desde clases particulares hasta compañía para un sábado a la tarde.

El segundo momento histórico en torno a la relación arte-uso aparece casi como corolario de Tucumán arde (experiencia de la que Jacoby fue partícipe) y se comprende dentro del pedido vanguardista de restituir a la esfera de la praxis vital los elementos separados de la cultura. Se trata del manifiesto de la revista SOBRE (1969):

A SOBRE no lo queremos intacto. Queremos que se deshaga, que se gaste, que se arroje como una granada, que sea un arma. SOBRE no es sólo para leer: es para usar. No lo guarde en 
un cajón ni lo coleccione en su biblioteca. [...] Si al cabo de una semana SOBRE está intacto y usted no ha discutido, no ha pensado, no se ha reunido $P A R A H A C E R A L G O$ es que no ha sabido usarlo. En cuyo caso, por favor, no lo compre más: hay muy pocos ejemplares circulando (JACOBY, 2011, p. 125, subrayado mío, mayúsculas del original).

Aun cuando la retórica de SOBRE en general responda punto por punto con la del manifiesto vanguardista y se lea, como señalaba, en el marco de la oposición entre la figura del artista o el intelectual y la militancia, es interesante el retorno de dicha valoración sobre el uso asociada a la revista como plataforma social de conocimiento. La temprana mención al respecto, abonaría la tesis de Longoni citada en el prólogo, mostrando una insistencia del artista en la concepción del arte como dispositivo social que presupone la centralidad de su medialidad, o mejor dicho, que equipara la obra con el medio de comunicación, como acto. ${ }^{12}$ Los dos casos, a su vez, enfatizan el rechazo a un capital acumulado y la evaluación del arte en base a su capacidad circulante (en el manifiesto: “[...] no lo compre más: hay muy pocos ejemplares circulando [...]" o en la ironía: “[...] usted puede convertirse en un especulador venus y acumular grandes cantidades de estos billetes").

\section{Usos de archivo}

Ahora bien, en vistas a la elaboración de una retrospectiva ¿de qué maneras el archivo podría convertirse en un medio de producción y no quedar anclado a su valor de exposición? ¿Cómo se establecería esta relación entre el arte como dispositivo de uso y su archivo?

En el año 2005, durante el Foro Internacional de Expertos de Arte de ARCO, en una sesión específica convocada por Laddaga y Carlos Basualdo, Jacoby resumía el problema de dar cuenta retrospectivamente de estas experimentaciones, claramente herederas de las búsquedas ligadas a la desmaterialización en el arte. Allí hablaba acerca de la imposibilidad de plasmar en imagen procesos artísticos 
colectivos. A pesar de que en ella radicase su diferencia sustancial, sólo mediante la elaboración de un relato, aun cuando fuera siempre incompleto, se podría intentar reconstruir esos acontecimientos:

\begin{abstract}
Tenemos aquí, entonces, una evidente paradoja. Por una parte, los proyectos de Comunidades Experimentales transcurren en un campo extremadamente concreto de situaciones sociales, cuyas acciones y relaciones son irrepresentables, no figurables, prácticamente inenarrables en su extrema variedad, riqueza y complejidad de prácticas. Por otra parte, para circular en el campo de la cultura, de los receptores interesados, de los teóricos, de los artistas y las agencias de distribución, financiación, etcétera, necesitan convertirse en pequeñas monedas míticas como la que acabo de acuñar al relatar Tucumán Arde. (JACOBY, 2011, p. 437-438, el subrayado es mío) ${ }^{13}$
\end{abstract}

Aquí se marca una función radical del archivo en tanto relato construido con posterioridad a una obra cuyos límites en torno a la autoría y a la objetualidad se difuminan sobre la esfera de la práctica. Si no existe obra que pueda circular como mercancía, será el relato y con ello, el archivo que lo sustenta, aquello que se convierta en "moneda" de circulación. Uno de los usos del archivo, entonces, reside en la articulación de dicha narrativa con el fin de intervenir en el campo de la cultura (de los teóricos, los interesados) y de funcionar como instrumento para obtener financiación. El archivo acuña su propio relato mítico de intercambio. Y esto supone, dirá Jacoby en otra oportunidad, que el arte que se entienda como político debe revisar a cada momento cómo encuentra su financiamiento en un mercado internacional en el cual el denominado "arte político" o "arte social” es un rubro sumamente redituable (JACOBY, 2011, p. 426).

Del uso de la práctica artística como dispositivo de intercambio social, pasamos entonces al uso de los archivos como producción de memoria y de autoabastecimiento. En tanto construcción de legibilidad de los fragmentos y los vacíos, el archivo conecta las partes con la investigación, ${ }^{14}$ sin alejarse de la dinámica de la red. En el caso de El deseo... el relato se presenta a los lectores, bajo la metáfora del libro-máquina, como retícula de posicionamientos ideológicos,

Anos 90, Porto Alegre, v. 21, n. 40, p. 311-331, dez. 2014 
vinculaciones personales y acontecimientos históricos. ${ }^{15}$ Pero más allá de la cita explícita a Deleuze, donde el lector se encontraría menos con una narración completa que con un sistema de operaciones y terminales, el libro asume para sí cierta maleabilidad pedagógica en su operatoria de diccionario, de manual, de cartografía. No es sólo la maquinaria Jacoby la que se comparte en El deseo... sino también determinadas claves, puestas a punto y en común, de todos los términos, las personas o los conceptos que recorrieron su obra a lo largo de más de cuarenta años, lo que supone, en su caso, la confección de diversos panoramas históricos del arte argentino.

Finalmente, habría un último sentido en la valoración del uso del archivo que se observa sólo después de la producción del libro como una nueva obra. Tiene que ver con el efecto de relato que, como citábamos al comienzo en las palabras de Farge, emerge no sólo de la constatación de acontecimientos o del encuentro con las reliquias, sino, inevitablemente, de la dimensión subjetiva que elabora con ellas una narración singular: "Apareció en mi archivo una caja que no frecuento para nada. Contiene cientos y cientos de páginas mecanografiadas y fechadas en los ' 80 , con divagaciones fragmentarias acerca de cualquier cosa: introspecciones, reflexiones sobre las discotecas y las fiestas, sobre el dinero falso y la inflación. Varias anticipan proyectos u obras posteriores" (JACOBY, 2011, p. 353).

¿Apareció? ¿Cuándo? ¿En dónde? ¿Delante de quién? Como varias otras, esta escena del artista repasando sus papeles, resulta sumamente dinámica, ya que crea en el lector la ilusión de atestiguar el momento de recolección y procesamiento de los documentos y nos conduce además a una constante de su prosa: su insistencia, a lo largo de los años, en la memoria y la evaluación del pasado. En el año 2000, Jacoby pensó las "estrategias de la alegría" como modos de irrupción del cuerpo en la escena urbana durante y después de la dictadura, en el marco de la cultura underground de los '80 (410). Pero a finales de los ' 80 , retomó los años sesenta como espacio-tiempo mítico, silenciado abruptamente (307). Y durante los comienzos de la democracia realizó un análisis sociológico pormenorizado sobre el miedo (275). ${ }^{16}$ La lista de ejemplos continúa: si el libro es una retrospectiva sobre su obra, habrá que aclarar que buena parte de su obra escrita resulta una permanente retrospectiva, que vuelve una

Anos 90, Porto Alegre, v. 21, n. 40, p. 311-331, dez. 2014 
y otra vez sobre las acciones artísticas y su relación con la historia. Esta dinámica recuerda las observaciones de Hal Foster (2004) en torno al impulso archivístico de ciertos artistas contemporáneos, para quienes conectar lo desconectado, a través de la investigación del pasado, reinstalaba menos una melancolía que una dimensión utópica, instituyente, de escenarios alternativos de vida. ${ }^{17}$ Las observaciones históricas en los textos de Jacoby (muchos de los cuales, es obligatorio decirlo, fueron escritos a pedido, por distintos medios o eventos) descubren una faceta archivística singular dentro de su obra. Una práctica que diverge de la producción de dispositivos de socialidad, aunque igualmente se encuentre dirigida a la intervención en el presente, esta vez, desde la escritura. No se trata exactamente de que El deseo nace del derrumbe permita descubrir o rescatar una relación entre arte y textualidad como una zona de contaminación previa, o que la productividad del archivo se circunscriba a la multiplicación de textos, poéticos, teatrales, ensayísticos, autobiográficos. Sino que permitiría detectar zonas de coexistencia que, junto al valor de la acción, inmediata e irregistrable, destinan un valor a los textos en tanto reserva de uso para el futuro. Este valor, que tampoco podría explicarse plenamente en virtud de la importancia que otorgaron los diversos conceptualismos a la dimensión proyectual del arte (FREIRE, 2006); apuntaría, más precisamente, a pensar un estado de las artes en el que tal vez ya no resulte posible evaluar la eficacia de las prácticas sin calcular la productividad de sus archivos, más allá (o tal vez junto con) el indudable efecto legitimante que la escritura imprime sobre aquello que en determinado momento histórico parecía contingente.

\section{Consideraciones finales}

La multiplicación de retrospectivas y documentales que desde comienzos del 2000 comienza a organizar en archivos experiencias artísticas, políticas y vitales sumamente dispersas y escasamente registradas, particularmente de los períodos entre finales de los años sesenta y la década del ' 80 , posee varios efectos en la cultura que

Anos 90, Porto Alegre, v. 21, n. 40, p. 311-331, dez. 2014 
obligan a revisar la dicotomía vanguardia artística/musealización en términos diferentes a los presupuestos que las propias vanguardias sostenían. ${ }^{18}$ Los objetos en dispersión que los relatos reconstructivos recogen se situaron en un entramado complejo de marginalidad, contracultura, políticas del cuerpo, formas de la teatralidad o de la vocalidad; su museificación creciente, antes que reafirmarlos en el marco del conceptualismo o la performance, señalaría un desplazamiento de su acción hacia las posibilidades abiertas por los archivos, dispuestos como usinas productivas y formas de bien común (BENKLER, 2010).

Entre el museo como espacio de consagración y como plataforma de espectacularización masiva parecería abrirse entonces una brecha, cuya dinámica podría extenderse hacia más de un ámbito de actuación. Como señalaba la investigadora brasilera Cristina Freire cuando describía las particularidades de los archivos pertenecientes al arte conceptual latinoamericano, la circulación de determinadas obras inobjetuales supuso durante años, una "dialética interessante entre museu, biblioteca e casa, domínios públicos em espaços privados" (2006, p. 73). Los efectos de esta dinámica descentralizada hoy se encuentran asociados a la elaboración de estrategias de uso de los archivos y a su capacidad de producir relatos que intervengan en el presente y respondan a un sentido instituyente, menos interesado por la crítica a la institución - el derrumbamiento del Museo como entidad de albergue totalizador ya está dado por sentado, según advierte Foster (2004, p. 5) - que por la instauración de nuevas formas de organización, intelección y transmisión de sus historias.

En esta oportunidad, nos hemos focalizado en la valoración en torno a los archivos de Jacoby. El entramado discursivo sobre el uso, presente como vimos desde finales de la década del sesenta, estaría atravesando cada una de las producciones y los registros, actuaría como su forma de sistematización, funcionaría, finalmente, como el verdadero archivo. 


\section{THE ARCHIVE AS A PRODUCER: THE PLACE OF USE IN EL DESEO NACE DEL DERRUMBE, BY ROBERTO JACOBY}

Abstract: During the 2000s, several artistic experiences, poetics and politics of Argentine vanguards of ' 60 and countercultural movements of democratic recovery process have been the subject of numerous investigations, retrospective exhibitions, archives and documentaries. The condition of this series (certainly expansive), brings an observation about the weight on the notion of archive: not only as a meeting and debit set of documents, but as ideal conceptual tool for thinking about the material issues in the arts and in literature. This article addresses, from a Foucauldian perspective of the archive (such as emergency regulations systematization and speeches), a network discourse about the role of the archive as a producer not only of critical stories about the task of archiving, but a particular device as common cultural use. Such a device would intervene in the forefront avant-garde/musealization opening new problematization of politics. This is tracked in the volume "El deseo nace del derrumbe. Acciones, conceptos y escritos” by Roberto Jacoby (Ana Longoni, ed.) (2011), different times in which strategy use was linked to his artistic practice.

Keywords: Archives. Argentine avant-garde. Roberto Jacoby. Musealization. Artist's literature.

\section{Notas}

${ }^{1}$ Por nombrar sólo algunos ejemplos argentinos, entre el año 2000 y 2012 se podrían tener en cuenta los documentales biográficos de Oscar Bony, Liliana Maresca, Alejandro Kuropatwa, Néstor Perlongher, Batato Barea; las muestras retrospectivas de León Ferrari, Marta Minujín; Inventario 1965-1975, la exposición del archivo de Tucumán Arde; la muestra y el libro El deseo nace del derrumbe, con los fragmentos y proyectos de obra de Roberto Jacoby, la exposición Perder la forma bumana. Una imagen sísmica de los ochenta en América Latina, con documentos de las acciones artístico-políticas de los finales de las dictaduras más sangrientas del continente; Mataderos, la compilación de los textos editados e inéditos de Ricardo Carreira. Aún sin ser exhaustivo, consideramos que el conjunto resulta sumamente representativo de un importante retorno museístico de experiencias limítrofes entre el arte, la corporalidad, la política, la sexualidad, hacia dentro del Archivo, entendiendo por ello, en sentido amplio, las exhibiciones de museos, sus catálogos, tanto como los relevamientos y las investigaciones así como los filmes documentales sobre estos períodos y biografías. Los documentales a los que nos referimos son: Alejandro Kuropatwa. Biografía documental. Dir.: Miguel Rodriguez Arias. Año: 2009. Video; Rosa patria. Dir: Santiago Loza. Año: 2008. Documental 
sobre Néstor Perlongher. Video; Frenesí, Dir: Adriana Miranda, video catálogo de la exposición retrospectiva sobre Liliana Maresca, presentada en el Centro Cultural Recoleta, Buenos Aires, del 4 al 27 de Noviembre de 1994; La peli de Batato. Directores: Peter Pank y Goyo Anchou. Documental. 150 minutos. 2010. Cerca de Bony, Director: Andrés Denegri, 30 minutos, 2006. Las exposiciones: León Ferrari. Antológica, Museo de Bellas Artes J.B. Castagnino, 2008; Marta Minujin. Obras 1959-1989, MALBA, 2010; Inventario 1965-1975. Archivo Graciela Carnevale, CCPE, 2008, El deseo nace del derrumbe. Acciones, conceptos y escritos, Museo Nacional de Arte Reina Sofía, 2011, Perder la forma bumana. Una imagen sísmica de los ochenta en América Latina, Museo Nacional de Arte Reina Sofía, 2012.

${ }^{2}$ En Argentina, la problemática viene promoviendo varios aportes en torno a la reactivación de la vanguardia del sesenta, su museificación y su transmisión. Uno de ellos fue el dossier de la revista Ramona, n. 82, de Julio de 2008: "Persistencia polémica. La herencia de la vanguardia de los sesenta", compilado por Ana Longoni con trabajos de Jaime Vindel, Longoni, Miguel Ángel López y Fernando Davis. De hecho, López ha continuado en esta línea con dos artículos más, resumidos en su trabajo: “ $¿ E s$ posible reconocer el conceptualismo latinoamericano" en revista Afterall Journal, n. 23, 2010.

${ }^{3}$ Frederic Jameson (1984) fue uno de los primeros en señalar el quiebre de la modernidad a partir de la reinserción, a modo de pastiche y objetos fetichizados, el retorno de procedimientos propios de la vanguardia de comienzos de siglo XX en la era del capitalismo tardío. Andreas Huyssen (1986), en su "Mapping the posmodernism", complejiza estos retornos para señalar ciertas esferas productivas y desfasajes temporales en la recepción de la vanguardia del ' 20 en Estados Unidos. Nicolás Bourriaud, más recientemente (2007), acuñó el concepto de "posproducción” para pensar la articulación de las artes después de los años “90, a modo del editor de video o el dj que seleccionaría y recolocaría fragmentos del archivo histórico.

${ }^{4}$ Cito a Benjamin en el señalamiento sobre la transformación radical a la que se veían sometidos los objetos de arte a partir de dicho valor exhibitivo: "A medida que las ejercitaciones artísticas se emancipan del regazo ritual, aumentan las ocasiones de exhibición de sus productos. La capacidad exhibitiva de un retrato de medio cuerpo, que puede enviarse de aquí para allá, es mayor que la de la estatua de un dios, cuyo puesto fijo es el interior del templo. [...] Con los diversos métodos de su reproducción técnica han crecido en grado tan fuerte las posibilidades de exhibición de la obra de arte, que el corrimiento cuantitativo entre sus dos polos se toma, como en los tiempos primitivos, en una modificación cualitativa de su naturaleza" (BENJAMIN, 1989, p. 29).

${ }^{5}$ Para un desarrollo sobre Tucumán arde ver los indispensables libros de LongoniMestman (2000) y Giunta (2001). 
6 "Desclasificar archivos no necesariamente implica desclasificar políticas de conocimiento. De hecho, la desclasificación puede tener como consecuencia la paralización de programas de investigación o la producción crítica, y la gestación de otra fiebre, cuyos síntomas ya pueden detectarse - me refiero a las compilaciones de documentos de artes" (GIUNTA, 2010, p. 23-24).

${ }^{7}$ Giunta define el estado "global" de las artes visuales en Latinoamérica y en el mundo a partir del 2001 como punto neurálgico (el 11 de septiembre de 2001 en EEUU, la crisis de 2001 en Argentina) que visibiliza una crisis de los paradigmas relativos al internacionalismo que se habían definido desde finales de los años sesenta. Este nuevo orden estaría marcado por la "bienalización" de las artes, que establece redes transnacionales de artistas y curadores a partir de los espacios urbanos y donde se ha asistido a una multiplicación exponencial de los museos y las instituciones de guarda. Aún sin proponérselo, los curadores de las bienales terminarían funcionando como intermediarios en la venta de las obras de arte, entre los compradores y los artistas (2011, p. 257-277).

${ }^{8}$ Me refiero particularmente a la labor de Longoni y la Red de Conceptualismos del Sur. El equipo que armó Inventario estuvo conformado por: Longoni, Carnevale, Fernando Davis y Ana Wandzik. El equipo del El deseo nace del derrumbe fue conformado por Davis, Daniela Lucena y Julia Risler.

${ }^{9}$ Para un análisis sobre la obra de Jacoby en interrelación con la idea de red y conectividad social, especialmente respecto del Proyecto Venus, ver Laddaga (2005, p. 89-95).

${ }^{10}$ Bajo la denominación "Archivo en uso", al finalizar la muestra en el Reina Sofía, se socializaron los escritos, proyectos, fotos, videos, audios y canciones de Jacoby a partir de distintas claves de abordaje hipertextual, en los siguientes Centros de documentación: la biblioteca del MNCARS y otros centros ligados a la Red Conceptualismos del Sur como el Museo del Barro (Asunción), el MUAC (México), la Maestría de Museología de la Universidad Nacional de Colombia (Bogotá) y el Centro de Investigaciones Artísticas (Buenos Aires). Ver Longoni (2011).

11 "Venus, moneda del deseo". El texto original fue presentado en el catálogo de la muestra Worthless (Invaluable) la Moderna Galerija de Ljubljana, 1999.

${ }^{12} \mathrm{Al}$ respecto, son elocuentes las palabras del propio artista en algunas entrevistas: "Mis primeras producciones se basaban en la idea de que la materialidad de los medios, de la ciudad, de las relaciones sociales en general, era susceptible de ser utilizada para fines artísticos. Esto es algo completamente obvio en la actualidad y lo practican cientos de artistas en todo el mundo. Para mí era un punto de partida. Una de las cosas que intenté desde Virus [el grupo de rock liderado por Federico Moura para el cual Jacoby escribía las letras] en adelante ha sido desarrollar medios hasta cierto punto autónomos, ya sea a través de las 'movidas' como las fiestas nómades en espacios no convencionales o a través de espacios

Anos 90, Porto Alegre, v. 21, n. 40, p. 311-331, dez. 2014 
publicitarios o de ropa apropiados por el arte. O como en el caso de ramona o Proyecto Venus, impulsando la formación de redes donde el medio, el emisor y el receptor se configuran en un mismo proceso" (377)

13 "Comunidades experimentales: archipiélagos en el océano de lo real", Ponencia leída en el encuentro mencionado. Publicada originalmente en revista ramona 51, Buenos Aires, junio de 2005, p. 26.

14 "La investigación genera archivo", sostuvo Ana Longoni (2011): "Cuando en 2004 iniciamos el trabajo de investigación sobre la producción de Roberto Jacoby no había archivo sino un caótico y desperdigado universo de papeles, publicaciones, grabaciones, filmaciones, dispersas en distintos lugares (la casa del artista, casas de amigos) y en franco riesgo de perderse. El primer desafío que enfrentamos fue, entonces, constituir el archivo, darle entidad como tal: reunir las partes, completar los blancos (que eran muchos) con trabajo de investigación, en el que recurrimos a los métodos de la historia oral (mediante la realización de extensas conversaciones con el artista) para ir otorgando legibilidad, datación, sentido a un cúmulo que parecía indescifrable e inabordable".

${ }^{15}$ El equipo de investigadores remite a la noción de "libro-máquina" elaborada por Gilles Deleuze y Félix Guattari en Mil mesetas: "En busca de explicitar la condición de "pequeña máquina" de este libro, proponemos una constelación de conceptos, líneas de pensamiento y obsesiones, que - a lo largo de los documentos reunidos - insisten, mutan, reaparecen. Dichos conceptos establecen entre sí relaciones de afinidad imposibles de sistematizar sin ser (aun más) arbitrarios.A continuación, algunas configuraciones o familias de vínculos (y, en algunos casos, el referente teórico del que provienen) entre los conceptos fetiche formulados o retomados por RJ, con la indicación de las páginas en las que se despliegan sus variantes. El lector sabrá proponer, en cada lectura, nuevas asociaciones u oposiciones" (JACOBY; LONGONI, 2011, p. 487).

${ }^{16}$ Los artículos son: "La alegría como estrategia", Zona erógena, n. 43 , 2000; "Los "60: historia guacha y mito zonzo", La hoja del Rojas, Año 1, n. 6, Centro Cultural Ricardo Rojas, noviembre de 1988; "Mirá cómo tiemblo", Crisis, n. 47, Buenos Aires, octubre de 1986, p. 3-12.

${ }^{17}$ Para Foster los artistas archivistas sostendrían su trabajo en base a conectar lo desconectado, recuperando momentos de la historia social o de los restos de la cultura para ver su potencial en el presente. Hacia el final del artículo, el crítico agrega una nueva pregunta hacia el problema. ¿Será que estas obras archivísticas buscan (del mismo modo que lo hace la estructura paranoica en términos freudianos), proyectar sentido en un mundo ominosamente arrastrado hacia lo mismo y lo banal? "Might archival art emerge out of a similar sense of a failure in cultural memory, of a default in productive traditions? For why else connect so feverishly if things did not appear so frightfully disconnected in the first place?" (FOSTER, 2004, p. 22)

Anos 90, Porto Alegre, v. 21, n. 40, p. 311-331, dez. 2014 
El archivo como productor: el lugar del uso...

${ }^{18}$ En "Escapar de la amnesia: los museos como medio de masas", Huyssen sostenía que no podía descontarse cierto efecto de "victoria pírrica" (2007, p. 55) en el ingreso absoluto de las vanguardias a los Museos. Sería conveniente, sostenía, desarticular una mirada sobre los éxitos o los fracasos de la vanguardia sustentada solamente en base a las propias evaluaciones museísticas. Una lectura que escapara a estos protocolos, decía, dejaría en evidencia que algunas de sus absorciones hacia dentro de los museos habían ocasionado un efecto inesperado, desde la propia transformación democratizadora de la institución - la apertura de los límites que rodeaban una élite social -, hasta su posibilidad ambivalente de reelaborar narrativas múltiples o volverse centro de grandes espectáculos.

\section{Referencias}

AGAMBEN, Giorgio. Profanaciones. Buenos Aires: Adriana Hidalgo, 2005.

AMIGO, R.; DOLINKO, S.; ROSSI, C. Palabra de artista: Textos sobre arte argentino 1961-1981. Buenos Aires: Fundación Espigas - Fondo Nacional de las Artes, 2010.

BENJAMIN, Walter. La obra de arte en la era de la reproductibilidad técnica. In: Discursos interrumpidos I. Madrid: Taurus, 1989.

BENKLER, Yochai. La economía política del procomún. Novática: Revista de la Asociación de Técnicos de Informática, n. 163, p. 6-9, 2003.

BOURRIAUD, Nicolas. Postproducción. Buenos Aires: Adriana Hidalgo, 2007.

CARNEVALE, G. et al. Inventario 1965-1975: Archivo Graciela Carnevale. Rosario: CCPE/AECID, 2008.

DERRIDA, Jacques. Mal de archivo: Una impresión freudiana. Madrid: Trotta, 1997.

FARGE, Arlette. La atracción del archivo. Valencia: Institució valenciana d'estudis i investigació, 1991.

FOSTER, Hal. An Archival Impulse. October, n. 110, p. 3-22, autumn 2004.

FOUCAULT, Michel. La arqueología del saber. México: Siglo XXI, 1979.

FREIRE, Cristina. Arte conceitual. Rio de Janeiro: Jorge Zahar Editor, 2006.

GARCÍA CANCLINI, Néstor. Culturas bíbridas: Estrategias para entrar y salir de la modernidad. Barcelona: Paidós, 2001.

Katz, 2010.

. La sociedad sin relato: Antropología y estética de la inminencia. Madrid:

Anos 90, Porto Alegre, v. 21, n. 40, p. 311-331, dez. 2014 
GIUNTA, Andrea. Vanguardia, internacionalismo y politica. Buenos Aires: Paidós, 2001. . Escribir las imágenes: Ensayos sobre arte argentino y latinoamericano. Buenos Aires: Siglo XXI, 2011.

HUYSSEN, Andreas. Mapping the Postmodern. New German Critique, n. 33, p. 5-52, autumn 1984.

. Escape from Amnesia: The Museum as Mass Medium. In: Twilight Memories: Marking Time in a Culture of Amnesia. Londres y Nueva York: Routledge, 1995. p. 13-35.

JACOBY, R.; LONGONI, A. El deseo nace del derrumbe: Acciones, conceptos, escritos. Buenos Aires - Madrid: Adriana Hidalgo - MNCARS - La Central, 2011.

JAMESON, Fredric. The Cultural Logic of Late Capitalism. New Left Review, n. 146, p. 59-92, 1984.

LONGONI, Ana. Politicas de Archivo desde la Red Conceptualismos del Sur: la experiencia del Archivo en uso de Roberto Jacoby. Conferencia en el Seminario Políticas de archivo: La noción de archivo y las prácticas artísticas contemporáneas. Girona: Universidad de Girona, 2011.

LONGONI, A.; MESTMAN, M. Del Di Tella a Tucumán Arde. Buenos Aires: El cielo por asalto, 2000.

Recebido em: 20/06/2013

Aprovado em: 03/12/2013 